Научная статья

УДК 614.253 .83

DOI 10.18101/2304-4446-2021-4-24-33

\title{
КАДРОВОЕ ОБЕСПЕЧЕНИЕ СИСТЕМЫ ЗДРАВООХРАНЕНИЯ РЕСПУБЛИКИ БУРЯТИЯ В УСЛОВИЯХ ПАНДЕМИИ: СОСТОЯНИЕ И ПРОБЛЕМЫ
}

\author{
(C) Башкуева Елена Юрьевна \\ кандидат исторических наук, \\ Бурятский научный центр СО РАН \\ Россия, 670047, г. Улан-Удэ, ул. Сахъяновой, 8 \\ frombear@mail.ru
}

\begin{abstract}
Аннотация. В статье представлен анализ кадрового обеспечения системы здравоохранения Республики Бурятия в условиях пандемии новой коронавирусной инфекции. Использованы ведомственные данные Министерства здравоохранения Республики Бурятия по кадровому обеспечению, материалы экспертных интервью с руководством и специалистами Министерства здравоохранения Республики Бурятия $(\mathrm{N}=10)$, проведенных в первом полугодии 2021 г. В исследовании применены следующие методы: аналитический, статистический, SWOT - анализ, экспертных оценок. Выявлено снижение показателей обеспеченности врачами и средними медицинскими работниками как в городской, так и в сельской местности, увеличение коэффициентов совместительства врачей. Выполнен SWOT-анализ кадрового обеспечения системы здравоохранения Республики Бурятия. Сформулированы ключевые мероприятия для решения кадровых проблем региональной системы здравоохранения. Сделан вывод, что для полноценного решения проблем кадровой обеспеченности необходима реализация комплекса мероприятий с участием федеральных, региональных и муниципальных властей, медицинских организаций и медицинской общественности.

Ключевые слова: здравоохранение, кадры, кадровое обеспечение, дефицит, медицинская организация, врачи, средний медицинский персонал, Республика Бурятия.
\end{abstract}

\section{Для цитирования}

Башкуева Е. Ю. Кадровое обеспечение системы здравоохранения Республики Бурятия в условиях пандемии: состояние и проблемы // Вестник Бурятского государственного университета. Экономика и менеджмент. 2021. № 4. С. 24-33.

Состояние кадровых ресурсов здравоохранения Российской Федерации играет важнейшую роль в обеспечении населения доступной, качественной и безопасной медицинской помощью и особенно важно в современных условиях распространения новой коронавирусной угрозы. Проблемы кадровой обеспеченности российского здравоохранения анализировали в своих работах многие известные ученые - медики и организаторы здравоохранения [1; 3-6].

Как отмечает известный специалист в области организации здравоохранения, доктор медицинских наук В. М. Чернышев с соавторами, решение кадровой проблемы в здравоохранении - одно из важнейших направлений в совершенствовании организации оказания медицинской помощи населению в современных условиях. Вместе с тем в связи с переходом к рыночным отношениям сложившаяся десятилетиями старая система подготовки и насыщения кадрами в здраво- 
E. Ю. Башкуева. Кадровое обеспечение системы здравоохранения Республики Бурятия в условиях пандемии: состояние и проблемы

охранении уже давно не работает, а новая - не создана. А лозунг «кадры решают все» по-прежнему актуален [5].

Авторитетная российская газета «Коммерсантъ» в июле 2021 г. публиковала материалы о том, что власти отдельных регионов признали, что пандемия обострила дефицит медицинских кадров ${ }^{1}$. По оценке издания, врачей не хватает в большинстве регионов, а особо остро дефицит ощущается в службе скорой помощи.

Ключевой проблемой здравоохранения Республики Бурятия, до сих пор не получившей кардинального решения, является недостаточная обеспеченность отрасли квалифицированным персоналом [2]. Министерство здравоохранения Республики Бурятия (далее - РБ) ежегодно выделяет в качестве основных направлений развития отрасли укрепление кадрового потенциала, включающее мероприятия по подготовке, повышению квалификации и профессиональной переподготовке медицинских работников, повышению престижа медицинской профессии, привлечению и закреплению медицинских работников в государственные медицинские организации РБ, созданию условий для получения конкурентного уровня оплаты труда. Однако кадровые проблемы остаются наиболее слабым звеном развития отрасли [2].

Материалами исследования стали статистические данные кадрового обеспечения системы здравоохранения Республики Бурятия, материалы экспертного опроса сотрудников Министерства здравоохранения Республики Бурятия о проблемах и перспективах кадровой обеспеченности в регионе $(\mathrm{N}=10)$. Основными методами исследования являются аналитический, метод описательной статистики, SWOT-анализ, экспертных оценок.

\section{Результаты исследования}

Здравоохранение Республики Бурятия уже много лет испытывает нехватку квалифицированных медицинских кадров [2]. Учитывая ситуацию с пандемией, этот вопрос стоит очень остро. По данным мониторинга медицинских кадров Республики Бурятия, в разгар пандемии новой коронавирусной инфекции в 2020 г. дефицит врачей составлял 261 человек, средних медицинских работников - 512 .

Рассмотрим основные показатели кадровой обеспеченности системы здравоохранения Республики Бурятия. Численность работающих в сфере здравоохранения Республики Бурятия по итогам 2020 г. в сравнении с 2019 г. увеличилась на 79 чел. (0,3\%): с 22644 до 22 723. Отмечается ежегодное сокращение численности медицинского персонала — врачей уменьшилось на 29 чел. (0,8\%): с 3580 до 3 551, средних медицинских работников (СМР) - на 21 чел. $(0,2 \%)$ : с 9034 до 9 013, провизоров — на 2 чел. (2,5\%): с 80 до 78.

В то же время отмечается прирост численности младшего медицинского персонала на 454 чел. (25,7 \%): с 1766 до 2 220, фармацевтов - на 1 чел. (2,6\%): с 39 до 40, специалистов с высшим немедицинским образованием - на 7 чел. (5,4\%): с 129 до 136. Увеличение младшего медицинского персонала обусловлено прежде всего переводом из прочего персонала для ухода за больными в ко-

\footnotetext{
${ }^{1}$ Острая врачебная недостаточность // Коммерсанть. 2021. № 131(7093). URL: http:// www.kommersant.ru doc/4919073 (дата обращения: 13.09.2021). Текст: электронный.
} 
видных госпиталях. В связи с этим уменьшилась численность прочего персонала на 331 чел. $(4,1 \%)$ : с 8016 до 7685.

Таблица 1

Численность работающих в государственных медицинских организациях здравоохранения (с лицами, находящимися в декретном и долгосрочном отпуске) в 2018-2020 гг.

\begin{tabular}{|c|c|c|c|c|c|}
\hline & \multirow[t]{2}{*}{2018} & \multirow[t]{2}{*}{2019} & \multirow[t]{2}{*}{2020} & \multicolumn{2}{|c|}{$\begin{array}{c}\text { Динамика, 2020/ } \\
2019\end{array}$} \\
\hline & & & & абс.4 & $\%$ \\
\hline Bcero, в том числе: & 22818 & 22644 & 22723 & +79 & $+0,3$ \\
\hline - врачи & 3658 & 3580 & 3551 & -29 & $-0,8$ \\
\hline - средний медицинский персонал & 9153 & 9034 & 9013 & -21 & $-0,2$ \\
\hline - младший медицинский персонал & 1833 & 1766 & 2220 & +454 & $+25,7$ \\
\hline - провизоры & 70 & 80 & 78 & -2 & $-2,5$ \\
\hline - фармацевты & 38 & 39 & 40 & +1 & $+2,6$ \\
\hline $\begin{array}{l}\text { - специалисты с высшим немеди- } \\
\text { цинским образованием }\end{array}$ & 106 & 129 & 136 & +7 & $+5,4$ \\
\hline - прочие & 7960 & 8016 & 7685 & -331 & $-4,1$ \\
\hline
\end{tabular}

Источник: данные Республиканского медицинского информационно-аналитического центра Министерства здравоохранения Республики Бурятия (РМИАЦ МЗ РБ)

По данным таблицы 2, в 2020 г. в сравнении с 2019 г. численность врачей уменьшилась на 29 чел.: с 3580 до 3551 (0,8\%), согласно отчетной форме № 30 (с лицами, находящимися в декретном и долгосрочном отпусках). Приток врачей зарегистрирован в республиканских медицинских организациях на 64 чел. (4,5\%): с 1417 до 1 481. Отток врачей отмечается в районах на 28 чел. (2,8\%): с 993 до 965, в медицинских организациях г. Улан-Удэ — на 65 чел. $(5,6 \%)$ : с 1170 до 1105 .

Таблица 2

Численность врачей Республики Бурятия за 2018-2020 гг.

(абсолютные значения, чел.)

\begin{tabular}{|l|c|c|c|c|c|}
\hline & 2018 & 2019 & 2020 & \multicolumn{2}{|c|}{$\begin{array}{c}\text { Динамика, } \\
2020 / 2019\end{array}$} \\
\cline { 4 - 6 } & & & & абс.ч & $\%$ \\
\hline РБ, в том числе: & & & & $\mathbf{3 5 8}$ & $\mathbf{- 0 , 8}$ \\
\hline - районы & $\mathbf{3 6 5 8}$ & $\mathbf{3 5 8 0}$ & $\mathbf{3 5 5 1}$ & $\mathbf{- 2 9}$ & $-2,8$ \\
\hline - г. Улан-Удэ & 1103 & 993 & 965 & -28 & $-5,6$ \\
\hline - республиканские МО & 1168 & 1170 & 1105 & -65 & $+4,5$ \\
\hline В т. ч. сельское здравоохранение & 1387 & 1417 & 1481 & +64 & $-4,4$ \\
\hline
\end{tabular}

Источник: данные РМИАЦ МЗ РБ

В целях обеспечения населения сельской местности медицинской помощью в Бурятии реализуется программа «Земский врач» (ч. 12.1 ст. 51 федерального за- 
E. Ю. Башкуева. Кадровое обеспечение системы здравоохранения Республики Бурятия в условиях пандемии: состояние и проблемы

кона от 29.11.2010 г. № 326-Ф3 «Об обязательном медицинском страховании в Российской Федерации»). За период 2011-2019 гг. по программе «Земский врач» привлечено и закреплено на последующие 5 лет в районах республики 908 молодых специалистов (2011-2012 гг. - 321 врач, 2013 г. - 102, 2014 г. - 52, в 2015 г. - 70, в 2016 г. - 100, 2017 г. - 124, 2018 - 97, $2019-42)$. В 2020 г. трудоустроено 88 врачей и 30 фельдшеров, процент исполнения составил 100 . Вместе с тем опрошенные нами эксперты из числа сотрудников Министерства здравоохранения Республики Бурятия отметили, что участники программы «Земский врач» сталкиваются с большими трудностями при переезде в сельскую местность, в том числе с жилищными, бытовыми, социокультурными проблемами. Эффективный механизм решения этих проблем успешно применяется лишь в отдельных селах и действительно способствует долговременному закреплению врача, а в своей основной массе участники программы стремятся по истечении срока ее действия переехать в города.

Вместе с тем не только федеральный, но и региональный бюджет несет расходы для решения кадровых проблем здравоохранения. Так, в рамках республиканской подпрограммы «Кадровое обеспечение системы здравоохранения» за счет средств республиканского бюджета предоставляются единовременные выплаты медицинским работникам наиболее дефицитных специальностей в размеpe 700 тыс. p., средним медицинским работникам неукомплектованных ФАПов по 200 тыс. p. (постановление Правительства РБ 16.10.2014 г. № 505). На указанные выплаты из республиканского бюджета выделено 46,6 млн р., из них в 2014 г. — 16,6 млн р., 2015 г. - 13,5 млн р., 2017 г. — 16,5 млн р., 2019 г. - 15,0 млн р. В 2020 г. финансирование составило 15 млн р., привлечены с 2019 по 2020 г. в первичное звено здравоохранения г. Улан-Удэ 33 врача дефицитных специальностей, в рамках реализации национальных проектов - 9 врачейспециалистов.

Реализация комплекса мероприятий по обеспечению системы здравоохранения Республики Бурятия медицинскими кадрами позволила увеличить следующие показатели за период с 2011 по 2020 г.:

- обеспеченность врачами на 10 тыс. нас. РБ - на 7,8\%: с 33,4 до 36,0, в районах — на 9,7\%: с 16,5 до 18,1, в сельском здравоохранении республики - на $8,6 \%$ : с 15,1 до 16,4 ;

- численность врачей, работающих в первичном звене в районах РБ, — на 87 чел.: с 592 до 679, показатель обеспеченности врачами первичного звена на 10 тыс. населения в районах — на 23,3\%: с 10,3 до 12,7, в целом по отрасли здравоохранения РБ - на 21,7\%: с 13,8 до 16,8;

- удельный вес врачей, работающих в первичном звене в РБ, - на 23,6\%: с 64,8 до 80,1 , в том числе в среднем по районам - на 9,4\%: с 64,3 до 70,4;

- обеспеченность врачей участковой службы на 10 тыс. нас. (участковыми терапевтами и педиатрами, врачами ВОП) в целом по республике - на 3,6\%: с 5,5 до 5,7, в среднем по районам - в 2 раза: с 2,7 до 5,4 ;

- обеспеченность специализированной первичной медико-санитарной помощью (без участковой службы) в целом в РБ - на 30,6\%: с 8,5 до 11,1 на 10 тыс. нас., в районах показатель вырос в 1,4 раза: с 5,4 до 7,3 на 10 тыс. нас.

По данным таблицы 3, за период 2019-2020 гг. показатель обеспеченности врачами на 10 тыс. нас. в здравоохранении Республики Бурятия снизился на 
1,1\%, составил 36,0 на 10 тыс. нас. (2019 г. - 36,4), что ниже показателя по стране за 2019 г. $(37,6)$ на 4,3\%, и ниже показателя ДФО за 2019 г. $(40,1)$ на $10,2 \%$.

Таблица 3

Обеспеченность врачами в 2018-2020 гг. на 10000 населения

(без учета аспирантов, клинических ординаторов и интернов)

\begin{tabular}{|c|c|c|c|c|c|c|c|c|c|c|}
\hline & \multirow{2}{*}{$\begin{array}{c}\text { Индикатор } \\
\text { РП РБ }\end{array}$} & \multirow[t]{2}{*}{2018} & \multirow[t]{2}{*}{2019} & \multirow[t]{2}{*}{2020} & \multirow{2}{*}{\begin{tabular}{|c}
$\begin{array}{c}\text { Динамика, } \\
\%\end{array}$ \\
$2020 / 2019$ \\
\end{tabular}} & \multicolumn{3}{|c|}{ Отклонение (в \%) от } & \multirow{2}{*}{$\begin{array}{c}\mathrm{P} \Phi \\
2019\end{array}$} & \multirow{2}{*}{$\begin{array}{l}\text { ДФО } \\
2019\end{array}$} \\
\hline & & & & & & индикатора & $\mathrm{P} \Phi$ & ДФО & & \\
\hline РБ, & 38,5 & 37,2 & 36,4 & 36,0 & $-1,1$ & $-6,5$ & $-4,4$ & $-10,2$ & 37,6 & 40,1 \\
\hline - г. Улан-Удэ & 26,7 & 26,1 & 26,1 & 24,4 & $-6,5$ & $-8,6$ & - & - & - & - \\
\hline - районы & 21,1 & 20,5 & 18,5 & 18,1 & $-2,2$ & $-14,2$ & - & - & - & - \\
\hline $\begin{array}{l}\text { - сельское здра- } \\
\text { воохранение } \\
\end{array}$ & - & 20,0 & 17,9 & 16,4 & $-8,4$ & - & $+15,5$ & $-0,6$ & 14,2 & 16,5 \\
\hline
\end{tabular}

Источник: данные РМИАЦ МЗ РБ

Показатель обеспеченности врачами по г. Улан-Удэ также снизился на 6,5\%: с 26,1 до 24,4 на 10 тыс. нас. Целевой индикатор по г. Улан-Удэ $(26,7)$ не достигнут, факт ниже на $8,6 \%$. Низкая обеспеченность врачами отмечается в ГАУЗ «Иволгинская ЦРБ» $(13,7)$, ГБУЗ «Петропавловская ЦРБ» $(15,0)$, ГБУЗ «Еравнинская ЦРБ» $(15,7)$, ГАУЗ «Заиграевская ЦРБ» $(15,8)$, ГБУЗ «Кяхтинская ЦРБ» $(15,9)$.

По данным таблицы 4, укомплектованность штатов врачей по занятым должностям снизилась на $12,1 \%$ и составила $69,9 \%$. При этом показатель ухудшился в г. Улан-Удэ на 9,3\% (с 78,1 до 70,8), районах республики - на 6,8\% (с 73,0 до $68,0)$, в республиканских МО — на 17,6\% (с 85,7 до 70,6).

Таблица 4

Укомплектованность врачебными должностями и коэффициент совместительства врачей за 2018-2020 гг.

\begin{tabular}{|c|c|c|c|c|c|c|c|}
\hline \multirow{2}{*}{ Показатель } & & \multirow[t]{2}{*}{2018} & \multirow[t]{2}{*}{2019} & \multirow[t]{2}{*}{2020} & \multicolumn{2}{|c|}{ Динамика (в \%) от } & \multirow{2}{*}{$\begin{array}{c}\text { Отклонениє } \\
\text { от РБ (\%) }\end{array}$} \\
\hline & & & & & $2020 / 2019$ & $2020 / 2018$ & \\
\hline \multirow{4}{*}{$\begin{array}{l}\text { Укомплектованность } \\
\text { занят. от шт. долж- } \\
\text { ностей, \% }\end{array}$} & РБ, $(\%)$, в т. ч.: & 82,2 & 79,5 & 69,9 & $-12,1$ & $-15,0$ & \\
\hline & - районы & 74,7 & 73,0 & 68,0 & $-6,8$ & $-9,0$ & $-2,7$ \\
\hline & - г. Улан-Удэ & 84,4 & 78,1 & 70,8 & $-9,3$ & $-16,1$ & $+1,3$ \\
\hline & $\begin{array}{l}\text { - республикан- } \\
\text { ские МО }\end{array}$ & 86,4 & 85,7 & 70,6 & $-17,6$ & $-18,3$ & $+1,0$ \\
\hline \multirow{4}{*}{$\begin{array}{l}\text { Укомплектованность } \\
\text { физ. лицами от шт. } \\
\text { должностей, \% }\end{array}$} & РБ в т. ч.: & 61,0 & 59,8 & 50,5 & $-15,6$ & $-17,2$ & \\
\hline & - районы & 59,1 & 54,6 & 49,2 & $-9,9$ & $-16,8$ & $-2,6$ \\
\hline & - г. Улан-Удэ & 64,2 & 63,6 & 57,8 & $-9,1$ & $-10,0$ & $+14,5$ \\
\hline & $\begin{array}{l}\text { - республикан- } \\
\text { ские МО }\end{array}$ & 60,0 & 61,0 & 47,0 & $-23,0$ & $-21,7$ & $-6,9$ \\
\hline \multirow{4}{*}{$\begin{array}{l}\text { Коэффициент сов- } \\
\text { местительства }\end{array}$} & РБ, в т. ч.: & 1,35 & 1,33 & 1,38 & $+3,8$ & $+2,2$ & \\
\hline & - районы & 1,26 & 1,34 & 1,38 & $+3,0$ & $+9,5$ & 0 \\
\hline & - г. Улан-Удэ & 1,31 & 1,23 & 1,22 & $-0,8$ & $-6,9$ & $-11,6$ \\
\hline & $\begin{array}{l}\text { - республикан- } \\
\text { ские МО }\end{array}$ & 1,44 & 1,41 & 1,50 & $+6,4$ & $+4,2$ & $+8,7$ \\
\hline
\end{tabular}

Источник: данные РМИАЦ МЗ РБ 
E. Ю. Башкуева. Кадровое обеспечение системы здравоохранения Республики Бурятия в условиях пандемии: состояние и проблемы

Ниже среднереспубликанского уровня $(69,9 \%)$ укомплектованность врачами по занятым должностям:

- в 12 ЦРБ (с наиболее низкими показателями в Кяхтинской - 45,2\%, Тункинской $-51,1 \%$, Баунтовской $-52,6 \%$, Курумканской $-54,8 \%$, Еравнинской $-55,6 \%$, Кижингинской- 59,5\%);

- 4 МО г. Улан-Удэ (с наиболее низкими показателями: ГБУЗ «Городская больница № $4-49,8 \%$, Станция скорой медицинской помощи - 58,2\%);

- 8 республиканских медицинских организациях (с наиболее низкими показателями: ГАУЗ «Центр восточной медицины» - 43,5\%, ГБУЗ «Республиканская инфекционная больница» - 46,6\%, ГБУЗ «Республиканский центр медицинской профилактики» - 46,6\%, ГБУЗ «Детская республиканская клиническая больница» - 57,4\%, ГБУЗ «Республиканский перинатальный центр» - 60,0\%).

Самый высокий показатель укомплектованность врачами по занятым должностям от среднереспубликанского:

- в 3 районах: Прибайкальском (82,8\%), Бичурском $(82,6 \%)$, Тарбагатайском $(80,8 \%)$;

- 4 городских МО: ГБУЗ «Стоматологическая поликлиника № 1» $(95,0 \%)$, ГБУЗ «Детская стоматологическая поликлиника» $(84,5 \%)$, ГБУЗ «Городская поликлиника № 1» (82,8\%), ГБУЗ «Стоматологическая поликлиника № 2» $(80,1 \%)$;

- 5 республиканских организациях: ГБУЗ «Республиканская стоматологическая поликлиника» (100\%), ГБУЗ «Республиканский врачебно-физкультурный диспансер» $(91,9 \%)$, ГБУЗ «Дом ребенка “Аистенок”» (86,7\%), ГБУЗ «Республиканский центр профилактики и борьбы со СПИД» $(83,2)$, ГБУЗ «Республиканский наркологический диспансер» $(80,0 \%)$.

Среднереспубликанский показатель укомплектованности штатов врачей физическими лицами уменьшился на 15,6\% (2020 г. - 50,5\%, 2018 г. - 59,8\%), в районах показатель снизился на 9,9\%: с 54,6 до 49,2. В г. Улан-Удэ регистрируется снижение укомплектованности штатов врачей физическими лицами на 9,1\%: с 63,6 до 57,8. При этом большое снижение показателя регистрируется в республиканских МО на 23,0\% (с 61,0 до 47,0),

Коэффициент совместительства врачей по РБ увеличился на $3,8 \%$ и составил 1,38 , в том числе в г. Улан-Удэ - 1,22 и республиканских $\mathrm{MO}-1,50$. В районах за последние 3 года коэффициент совместительства ежегодно увеличивается, в 2020 г. повысился на $3,0 \%$ и составил 1,38 .

Рассмотрим качественные характеристики медицинского персонала Бурятии на основе показателя его аттестованности (табл. 5).

По итогам 2020 г. из 3551 врача имеют квалификационную категорию 1176 $(33,1 \%)$, что несколько ниже, чем в 2019 г. $(33,3 \%)$, на $0,6 \%$, в т. ч. по районам наблюдается снижение на $2,5 \%$, по республиканским медицинским организациям - на 3,2 \%, по городским медицинским организациям - увеличение на $3,1 \%$. Показатель ниже, чем по стране, за 2019 г. $(42,5)$ на 22,1\%, и ниже показателя ДФО за 2019 г. $(42,9)$ на 22,8\%.

Высокий удельный вес аттестованных врачей регистрируется в следующих медицинских организациях: ГБУЗ «Республиканский центр профилактики и борьбы со СПИД» - 71,0 \%, ГБУЗ «Республиканский кожно-венерологический диспансер» - 64\%, Дом ребенка «Аистенок» - 60,0\%, Станция скорой медицинской помощи - 60,0\%, ГАУЗ «Республиканская клиническая больница им. 
Н. А. Семашко» - 54,9\%, Территориальный центр медицины катастроф $52,0 \%$, ГБУЗ «Детская республиканская клиническая больница» - 50,3\%. Наиболее низкий удельный вес: ГБУЗ «Городская больница № 2»- 0\%, Тарбагатайская ЦРБ - 4,2\%, Муйская ЦРБ - 9, 1, ГБУЗ «Республиканская стоматологическая поликлиника» - 10,2\%.

Таблица 5

Аттестованность врачей Республики Бурятия за 2018-2020 гг.

\begin{tabular}{|c|c|c|c|c|c|}
\hline Показатель & & 2018 & 2019 & 2020 & $\begin{array}{c}\text { Динамика, \% } \\
2020 / 2019 \\
\end{array}$ \\
\hline \multirow{4}{*}{$\begin{array}{l}\text { Всего аттестовано врачей } \\
\text { (абс.) }\end{array}$} & РБ, в т. ч.: & 1254 & 1191 & 1176 & $-1,3$ \\
\hline & - районы & 320 & 275 & 261 & $-5,1$ \\
\hline & - г. Улан-Удэ & 328 & 299 & 292 & $-2,3$ \\
\hline & - республиканские МО & 606 & 617 & 623 & $+1,0$ \\
\hline \multirow{4}{*}{$\begin{array}{l}\text { Удельный вес аттестован- } \\
\text { ных от всех врачей, \% }\end{array}$} & РБ, в т. ч.: & 34,3 & 33,3 & 33,1 & $-0,6$ \\
\hline & - районы & 29,0 & 27,7 & 27,0 & $-2,5$ \\
\hline & - г. Улан-Удэ & 28,1 & 25,6 & 26,4 & $+3,1$ \\
\hline & - республиканские МО & 43,7 & 43,5 & 42,1 & $-3,2$ \\
\hline \multirow{3}{*}{ Структура категорий, \% } & - высшая категория & 56,9 & 55,4 & 54,5 & $-1,6$ \\
\hline & - первая категория & 23,9 & 24,6 & 25,1 & $+2,0$ \\
\hline & - вторая категория & 19,2 & 20,0 & 20,4 & $+2,0$ \\
\hline
\end{tabular}

Источник: данные РМИАЦ МЗ РБ

Средний уровень аттестованности врачей по районам за 2020 г. - 27,0\%. Высокий показатель в следующих ЦРБ: Мухоршибирская - 46,3\%, Курумканская - 45,5\%, Кяхтинская - 41,4\%.

Преобладают врачи с высшей категорией - 648 чел. (18,2\% - от всех врачей и $55,1 \%$ - аттестованных), затем с первой - 297 чел. (8,4\% - от всех врачей и $25,2 \%$ - аттестованных) и со второй - 232 чел. $(6,5 \%$ - от всех врачей и $19,7 \%$ - аттестованных).

Таблица 6

Численность среднего медицинского персонала в сфере здравоохранения

Республики Бурятия за 2018-2020 гг. (абсолютные значения, чел.)

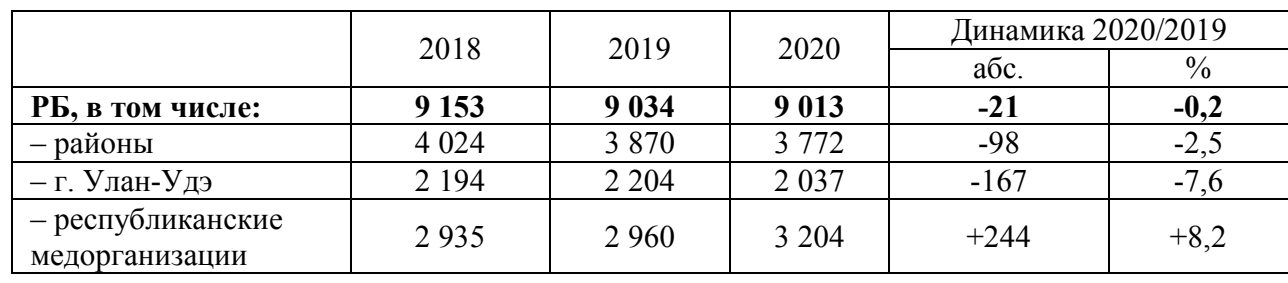

Источник: данные РМИАЦ МЗ РБ

По данным таблицы 6, последние 3 года ежегодно отмечается убыль численности среднего медицинского персонала (далее - СМР): за период 20182019 гг. - на 119 чел.: с 9153 до 9 034, за период 2019-2020 гг. — на 21 чел.: до 9013, или 0,2\%.

В том числе в 2020 г. снизилась численность СМР в сравнении с 2019 г. в районах — на 98 чел. (2,5\%): с 3870 до 3 772, и в г. Улан-Удэ - на 167 чел. (7,6\%): 
E. Ю. Башкуева. Кадровое обеспечение системы здравоохранения Республики Бурятия в условиях пандемии: состояние и проблемы

с 2204 до 2 037, но отмечено увеличение в республиканских организациях на 244 чел. (8,2\%): с 2960 до 3204.

В Республике Бурятия организовано целевое обучение специалистов по программам специалитета и программам ординатуры. Подготовка осуществляется в медицинских вузах Российской Федерации, в том числе в Медицинском институте ФГБОУ ВО «Бурятский государственный университет им. Доржи Банзарова» Министерства образования Российской Федерации (далее - БГУ). В 2020 г. поступили на первый курс с заключением договора о целевом обучении 177 студентов в 15 медицинских вузов Российской Федерации, в том числе 45 студентов в Медицинский институт БГУ. Обучаются в клинической ординатуре 115 врачей с заключением договора о целевой подготовке, из них 58 врачей поступили в 2020 г.

Подготовка среднего медицинского персонала осуществляется двумя образовательными организациями, реализующими программы среднего профессионального образования, подведомственными Минздраву Бурятии. В 2020 г. принято 438 студентов, из них 350 - по договорам о целевом обучении.

С учетом потребности в медицинских кадрах Министерством здравоохранения Республики Бурятия ежегодно формируется заявка на выделение целевых мест в медицинских вузах Российской Федерации и ССУЗах республики. В рамках целевого договора обучается 767 студентов в 13 медицинских вузах Российской Федерации, в Медицинском институте БГУ - 175 студентов.

В связи с пандемией возросла потребность в таких узких специалистах, как инфекционисты. До пандемии в республике работало 45 врачей-инфекционистов. Сейчас их штат увеличен почти вдвое за счет переобучения и мобилизации имеющихся кадров. Всего в период пандемии привлечено 415 врачей и 745 среднего медицинского персонала, 26 клинических ординаторов, 104 студента Медицинского института и 231 студент республиканских колледжей. Для ускоренной подготовки младшего персонала в медицинских колледжах организованы курсы. За особые заслуги в борьбе с коронавирусом 19 медицинских работников удостоены федеральными наградами, 77 - медалью по зову долга и сердца.

На основании проведенного статистического анализа и экспертного опроса выполнен SWOT-анализ кадрового обеспечения системы здравоохранения Республики Бурятия (табл. 7).

Таким образом, проведенное исследование показало, что система здравоохранения Республики Бурятия испытывает дефицит медицинских кадров: врачей и среднего медицинского персонала, особенно в сельских населенных пунктах. В период пандемии вследствие недостатка медицинских кадров региональные власти были вынуждены привлекать студентов Медицинского института БГУ и республиканских колледжей. Министерству здравоохранения РБ и подведомственным ему учреждениям предстоит большая организационно-методическая работа по решению кадровых проблем региональной системы здравоохранения. Ключевыми мероприятиями должны стать:

- снижение дефицита медицинских кадров, в том числе за счет снижения их оттока, особенно из сельских населенных пунктов;

- устранение дисбаланса в системе распределения медицинских кадров в трехуровневой системе оказания медицинской помощи;

- совершенствование системы практической подготовки медицинских работников; 
- усиление мер социальной поддержки медицинских работников;

- разработка комплекса мероприятий, направленных на повышение статуса врача и среднего медицинского персонала, на осознание медицинским работником потенциала профессии и ее перспектив, высокой социальной значимости.

Таблица 7

SWOT-анализ кадрового обеспечения системы здравоохранения Республики Бурятия

\begin{tabular}{|c|c|}
\hline Сильные стороны & Возможности \\
\hline $\begin{array}{l}\text { Высокий уровень квалификации медицин- } \\
\text { ских работников, в том числе руководите- } \\
\text { лей МО; } \\
\text { наличие базы подготовки кадров (Меди- } \\
\text { цинский институт БГУ, медицинские кол- } \\
\text { леджи); } \\
\text { преобладание молодых прогрессивных } \\
\text { специалистов, нацеленных на постоянное } \\
\text { повышение профессиональных компетен- } \\
\text { ций; } \\
\text { внедрение системы наставничества; } \\
\text { обмен опытом; } \\
\text { высокая сплоченность и командный дух } \\
\text { медицинского персонала }\end{array}$ & $\begin{array}{l}\text { Наличие Регионального центра компетен- } \\
\text { ций по качеству и безопасности медицин- } \\
\text { ской деятельности, Корпоративного уни- } \\
\text { верситета при Министерстве здравоохра- } \\
\text { нения РБ, деятельность которых направле- } \\
\text { на на повышение компетенций медицин- } \\
\text { ских работников; вступление в ДФО спо- } \\
\text { собствовало расширению социальной под- } \\
\text { держки населения (дальневосточная ипо- } \\
\text { тека, дальневосточный гектар) }\end{array}$ \\
\hline Слабые стороны & Угрозы \\
\hline $\begin{array}{l}\text { Дефицит медицинских кадров: врачей и } \\
\text { СМП, особенно в сельских территориях; } \\
\text { отток медицинских кадров, особенно из } \\
\text { сельских районов; } \\
\text { отсутствие опыта и компетенций молодых } \\
\text { специалистов; } \\
\text { низкая мотивация кадров; ошибки в работе; } \\
\text { высокий уровень эмоционального выгора- } \\
\text { ния, особенно в период пандемии }\end{array}$ & $\begin{array}{l}\text { Отток молодых специалистов в крупные } \\
\text { города РФ, } \\
\text { ухудшение социальной инфраструктуры } \\
\text { региона оказывает значительное влияние } \\
\text { на трудовой потенциал работников; } \\
\text { низкий престиж работы в медицинской } \\
\text { сфере; негативный образ медицинского } \\
\text { работника в общественном мнении и СМИ }\end{array}$ \\
\hline
\end{tabular}

Реализация данных мероприятий должна быть выстроена на основе единой, скоординированной работы федеральных, региональных и муниципальных властей, медицинских организаций и медицинской общественности.

\section{Литература}

1. Артюхов И. П., Шульмин, А. В., Добрецова Е. А. Дефицит врачебных кадров: есть ли перспективы для изменений // Социология медицины. 2017. Т. 16, № 2. С. 115-118. Текст: непосредственный.

2. Башкуева Е. Ю. Реализация государственной политики в области кадрового обеспечения системы здравоохранения Республики Бурятия // Вестник Бурятского государственного университета. Сер. Экономика и право. 2015. № 2а. С. 176-180. Текст: непосредственный.

3. Маринкин И. О., Кондюрина Е. Г., Аксенова Е. А. Совершенствование кадровой политики регионального здравоохранения // Регионология. 2020. Т. 28, № 3. С. 598-623. Текст: непосредственный. 
E. Ю. Башкуева. Кадровое обеспечение системы здравоохранения Республики Бурятия в условиях пандемии: состояние и проблемы

4. Чернышев В. М., Воевода М. И., Мингазов И. Ф. О несостоятельности кадровой политики в здравоохранении России // Сибирский научный медицинский журнал. 2019. Т. 43, № 6. С. 107-115. Текст: непосредственный.

5. Чернышев В. М., Стрельченко О. В., Мингазов И. Ф. Последствия реформирования здравоохранения в РФ (1990-2020 гг.). Проблемы и предложения // Оргздрав. 2021. Т. 7, № 2(24). С. 86-103. Текст: непосредственный.

6. Шейман И. М., Шевский В. И. Кадровая политика в здравоохранении: сравнительный анализ российской и международной практики // Вопросы государственного и муниципального управления. 2015. № 1. С. 143-167. Текст: непосредственный.

7. Шубцова Л. В., Махнова Н. А. Проблемы кадрового обеспечения региональной системы здравоохранения // Фундаментальные исследования. 2014. № 12, ч. 11. С. 24342439. Текст: непосредственный.

8. Щепин В. О. Обеспеченность населения Российской Федерации основным кадровым ресурсом государственной системы здравоохранения // Проблемы социальной гигиены, здравоохранения и истории медицины. 2013. № 6. С. 24-28. Текст: непосредственный.

Статья поступила в редакцию 21.10.2021; одобрена после рецензирования 29.10.2021; принята к публикации 01.11.2021.

\title{
STAFFING OF HEALTHCARE SYSTEM IN THE REPUBLIC OF BURYATIA AMIDST THE PANDEMIC: CURRENT STATE AND CHALLENGES
}

\author{
Elena Yu. Bashkueva \\ Cand. Sci. (History), \\ Buryat Scientific Center SB RAS \\ 8 Sakhyanovoy St., Ulan-Ude 670047, Russia \\ frombear@mail.ru
}

Abstract. The article considers the staffing of healthcare system in the Republic of Buryatia amidst the coronavirus pandemic. We have analyzed the departmental data of the Ministry of Health of the Republic of Buryatia on staffing, the materials of expert interviews with the administration and specialists of the Ministry of Health of the Republic of Buryatia $(\mathrm{N}=10)$ held in the first half of 2021, using the following methods: analytical, statistical, SWOT analysis, expert assessments. It was revealed a decrease in medical service density in both urban and rural areas, an increase in the coefficients of concurrent employment of doctors. We carried out a SWOT analysis of the staffing of healthcare system in the Republic of Buryatia, and formulated key measures to address personnel problems of the regional healthcare system. It has been concluded that in order to solve the problems of staffing, it is necessary to implement a set of measures with the participation of federal, regional and municipal authorities, healthcare organizations and the medical community.

Keywords: healthcare, personnel, staffing, shortage, healthcare organization, doctors, nursing staff, the Republic of Buryatia.

\section{For citation}

Bashkueva E. Yu. Staffing of Healthcare System in the Republic of Buryatia amidst the Pandemic: Current State and Challenges. Bulletin of Buryat State University. Economy and Management. 2021; 4: 24-33 (In Russ.).

The article was submitted 21.10.2021; approved after reviewing 29.10.2021; accepted for publication 01.11.2021. 